\title{
Quality of Life and Needs in Informal Caregivers of Elderly (ICE): Results From a Prospective Multicentric Open-label French Study
}

\section{Astrid Pozet ( $\square$ apozet@chu-besancon.fr )}

Centre Hospitalier Universitaire de Besançon

\section{Sophie Darnis}

Centre Léon Bérard

\section{Magalie Bonnet}

Université Bourgogne Franche-Comté

\section{Aurélia Meurisse}

Centre Hospitalier Universitaire de Besançon

\section{Tienhan Sandrine Dabakuyo-Yonli}

Plateforme Nationale Qualité de Vie et Cancer

\section{Catherine Lejeune}

Université Bourgogne Franche-Comté

\section{Philippe Fagnoni}

Centre Hospitalier Universitaire Dijon Bourgogne

\section{Maryse Gaimard}

Université Bourgogne Franche-Comté

\section{Patrick Manckoundia}

Centre Hospitalier Universitaire Dijon Bourgogne

Clémence Quibel

Pôle de gérontologie et d'innovation Bourgogne-Franche-Comté (PGI)

\section{Mélanie Marchand}

Centre Hospitalier Universitaire de Besançon

\section{Amélie Anota}

Centre Léon Bérard

\section{Virginie Nerich}

Centre Hospitalier Universitaire de Besançon

\section{Research Article}

Keywords: caregiver, elderly, chronic diseases, quality of life, burden, anxiety, depression, long-term care, needs, support 
Posted Date: February 16th, 2022

DOI: https://doi.org/10.21203/rs.3.rs-1349746/v1

License: (c) (i) This work is licensed under a Creative Commons Attribution 4.0 International License. Read Full License 


\section{Abstract}

Background. Better knowledge on caregivers is required to address their needs with dedicated support. The results from the ICE study explored the health-related quality of life (HRQoL) in caregivers of elderly with chronic disabilities, after social intervention or not.

Methods. Caregivers of patients ( $\geq 60$ years) with cancer, neurodegenerative disease, stroke, or agerelated macular degeneration were randomized 1:1 in the supportive intervention group (support from social workers and information booklet) or in the control group (information booklet only), and completed questionnaires (short form-36 questionnaire (SF-36), Hospital Anxiety Depression Scale (HADS), and Zarit Burden Interview (ZBI) quarterly (6-monthly for ZBI) during two years. Caregiver characteristics, and caregiver HRQoL assessment through SF-36, HADS, ZBI scores at baseline, at 12 months (M12) and 24 months (M24) on an individual and an aggregate level, were described using paired-t test comparisons, and minimal important difference. Longitudinal assessments of caregiver HRQoL over the two first years were reported.

Results. From 2015 to 2019, 179 caregivers supported patients with cancer ( $n=92,52 \%)$, Alzheimer ( $n=46$, $26 \%)$, Parkinson ( $n=20,11 \%)$ were randomized. No evidence differences in SF-36 PCS and MCS summary scores mean change over time, neither in HADS anxiety and burden ZBI scores were shown. However, HADS depression mean changes showed a clinically significant increase of 1.4 (4.0) at M12, and 1.7 (4.1) at M24 in control group.

Conclusion. Appropriate support need to be proposed to improve the global caregiver HRQoL, and reduce depression at 1 and 2 years.

Trial registration number: This study was registered retrospectively with ClinicalTrials.gov NCT02626377 on $9^{\text {th }}$ December 2015.

\section{Introduction}

In many industrialized countries, the increasing life expectancy in conjunction with the high prevalence of chronic diseases in ageing population has become a critical societal issue and consequently also a major policy concern. The need of long-term care or support directly dedicated to informal caregivers has intensified.(1) Although the self-recognition of caregiver is not obvious, informal care is becoming increasingly recognized in international policy circle at the European level and in France. A caregiver is defined as a "non-professional person who provides primary assistance with activities in daily life, either in part or in whole, toward a dependant person in his/her immediate circle." (2-4) About one third of caregivers declare to experience negative effects in their familial and social life, admit that they lack time to preserve leisure activities, and their psychological and physical health may be globally altered. The European Pillar of social rights in 2017 makes explicit the commitment to caregivers, including their right to flexible working and access to care services, and the importance to preserve employment, health, and well-being deserves to be outlined.(5-8) 
In Europe, the number of informal caregivers ranges from $10 \%$ up to $25 \%$ of the total population.[8] This estimation varies significantly between countries, and depends on how informal care is defined and measured.(9) In France, national surveys accounted for a total of 8 million informal carers in 2019, including 3.9 million of informal carers declared by people aged 60 years and over.(10)

The health-related quality of life (HRQoL) of caregivers is closely linked to the HRQoL of the helped person with chronic disease. From initial diagnosis, the disease may include successive phases of stabilisation and/or remission, and progressive decline and palliation, along with physical and psychological consequences. Profound changes in caregiver lifestyle are needed, with practical, organisational and potentially economic problems. All these changes and regular exposure to chronic stress may directly affect caregiver mental and physical health. Indeed, the expression of anxiety and depression symptoms, and care burden need to be closely monitored and are useful to detect early signs of health deterioration, for the caregiver himself and potentially jeopardizing the ability to care. Therefore, appropriate follow-up of caregiver health becomes increasingly relevant, to help caregiver to preserve its health status, and early identify and better manage personal difficulties.

The assessment of caregiver needs is an essential step to lay the foundation for adapted support development, with rationalized supply of timely, appropriate and efficient services. Large programs and studies are required to better identify the most vulnerable caregivers, which means to recognize caregiver needs, and define the most appropriate ways professionals and services (psychosocial, respite, training, education, long-term care) may adequately support them and timely and quantitatively respond to their needs.

The French prospective multicentric cohort of Informal Carers of Elderly (ICE) was initiated in 2015 at the regional level of Burgundy-Franche-Comté, representing $9 \%$ of the French national territory, and accounting for 2.8 million, i.e. $4.4 \%$ of the national population.(11) The ICE study contained an observational study which planned during 10 years (5-year enrollment, with 5-year follow-up) to recruit 7604 caregivers of patients with cancers, neuro-degenerative disease, age-related macular degeneration, stroke aged 60 years and older, and included a randomized interventional trial restricted to the first two years of entrance into the caregiver's role. This observational study defined as primary endpoint of the HRQoL assessment during the first 5 years, and the randomized study aimed to compare HRQoL at one year between groups.(12) Several amendments to the protocol were addressed to overcome barriers in caregiver recruitment, and to revise the initial objectives. Nonetheless, the steering committee decided to stop enrollment in May 2019. In this context, we used data from informal caregivers included to describe caregiver and patient characteristics, and caregiver involvement in patient everyday life. We report quantitative approaches evaluating caregiver HRQoL, anxiety and depression, and burden in caregivers receiving a supportive intervention or not, at one year, at two years and changes over the two-year period, on an individual and an aggregate level.

\section{Methods}




\section{Study population}

Eligible caregivers were 18 years and over, identified by the patient or self-identified as the primary caregiver, not employed by a healthcare organization, residing in Burgundy-Franche-Comté, able to understand and complete questionnaires. Caregivers belong to the immediate circle (family, friend or neighbor) of a patient aged 60 years or older with neuro-degenerative disease (idiopathic Parkinson's disease or Alzheimer disease) diagnosed in the last months (last 12 months and then amended to the last 24 months), cancer (breast, prostate, or colorectal), age-related macular degeneration, and neurovascular disease (stroke). Non-inclusion criteria were caregivers of patients living in institution, principal caregivers under legal protection. All caregivers provided written informed consent. Detailed inclusion/exclusion criteria have been previously published.(12)

\section{Intervention}

Caregivers were randomly assigned in a 1:1 ratio to the supportive interventional group or to the control group. Caregivers assigned in the supportive group received an intervention provided by a social worker and an information booklet. Caregivers randomized in the control group exclusively received the information booklet.

The intervention of a social worker was scheduled at 6, 12, 18 and 24 months (M6, M12, M18 and M24) after inclusion. The intervention consisted in a visit of one hour divided in two parts: firstly, qualify health difficulties encountered according to administration of the Linear Analogue Scale Assessment quality of life questionnaire.(13) Secondly, a standardized semi-directive interview aims to assess needs and detect early signs of burn-out. More details on social worker intervention were previously published.(12) Booklets provide concrete information on existing structures and support programs, and included concise information on local legislation, administrative procedures, daily life management and consequences related to the caregiving relationship.

\section{Administration of questionnaires}

All caregivers received questionnaires included HRQoL assessments using Medical Outcomes Survey Short Form-36 questionnaire (SF-36) for physical health component summary (SF-36-PCS), mental health component summary (SF-36-MCS), and detailed dimensions,(14-16) anxiety and depression with Hospital Anxiety Depression Scale (HADS),(17) and caregiver burden used Zarit Burden Interview (ZBI). (18-20) Scores were computed according to the respective recommendations. $(14,17,21,22)$ All questionnaires were self-administered quarterly except ZBI administrated six-monthly.

All scores for SF-36 subscales were computed on a 0 (worse HRQoL) to 100 (best HRQoL) point scale. The minimal important difference (MID) was defined as the smallest change in any scale within a patient (patient outcome self-identified as important) or at the group level. The MID was fixed at 5 points for SF-36.(23) HADS anxiety and depression reported a raw score using a 0 (absence of trouble) to 21 (severe trouble) point range, with a MID fixed at 1.32 point for the HADS anxiety score, and at 1.4 point for 
the HADS depression score.(24) The ZBI reported a raw score using a 0 (no burden) to 88 (severe burden) point range, and the MID for ZBI was defined as half of the standard deviation observed at baseline, as usually performed for scores with no previously determined MID. To note, increased SF-36 scores translated an improved status, and increased HADS and ZBI translated a decreased status.

\section{Endpoints}

The ICE study faced caregiver recruitment difficulties and prematurely discontinued. The final sample size of the reduced ICE cohort did not allow to perform the statistical analyses initially planned.(12) Specifically, the lack of power prevent any comparisons between groups. Nevertheless, the initial primary and secondary endpoints were adapted to the current context and present results per randomized group: 1) SF-36 PCS and MCS summary scores mean change at M12 and M24 compared to baseline2) mean change at M12 and M24 for the subscales scores of the SF-36, HADS and ZBI compared to baseline; 3 ) the rates of caregivers with deteriorated, stabilized, and improved HRQoL, with SF-36 PCS and MCS, and SF-36 subscales, HADS and ZBI scores according to their respective MID at M12 and M24; and 4) longitudinal assessments of caregiver HRQoL, anxiety/depression and burden over the two years.

\section{Statistical analyses}

All analyses were performed using a modified intention-to-treat principle, i.e. including all caregivers allocated to randomization, with completed SF-36 questionnaire at baseline. The analyses included all data available at each considered timepoint. Only descriptive analysis per group were conducted.

Socio-demographic and clinical characteristics were described in the global population and in each randomization group. Categorical variables were expressed using number and frequency $(n, \%)$ and continuous variables with median (min-max). Mean (standard deviation)/median (min-max) scores were described at each timepoint in both groups. Mean changes in SF-36, HADS, and ZBI scores from baseline to $\mathrm{M} 12$ and M24, are presented per group with paired t-test fixed at $5 \%$ for statistical significance.

At the aggregate level, we reported in each group the rate of caregivers with SF-36-PCS, SF-36-MCS, HADS, and ZBI score changes from baseline to M12 and from baseline to M24, categorized as stable, deteriorated, or improved according to their respective MID.

Mixed models for repeated measures were used for longitudinal analysis of HRQoL including all timepoints until M24 and included the following variables: randomization group, time, allocation-by-time interaction, adjusted on baseline score, and baseline score-by-time interaction. Random effects on intercept and time were used in order to reflect individual variations at baseline and over time. Adjusted mean changes at M12 and M24 were reported with 95\% confidence interval (CI) for SF-36-PCS and -MCS scores, HADS anxiety and depression, and burden, per group. Statistical and MID clinical significances were indicated.

Analyses were performed using SAS version 9.4 software (SAS Institute Inc., Cary, NC, USA). 


\section{Results}

From October 2015 to May 2019, 183 caregivers were recruited and 179 were randomly assigned in the supportive intervention group $(n=90)$ or in the control group $(n=89)$. Each caregiver enrolled had completed the questionnaires at inclusion and the completion rates were $70 \%$ and over in each group, at each timepoint from M3 and up to M24 (Figure 1).

\section{Caregiver characteristics at baseline in the global population and per group}

The median age of caregivers was 65 (29-92) years and more caregivers were women $(n=120,67 \%)$ identified as the spouse $(n=118,66 \%)$, or as child helping mother/father $(n=42,23 \%)$. Caregivers were providing help to patients (median age: 73, 60-94), including 92 (52\%) patients with cancer, 66 (37\%) with neurodegenerative disease, 11 (6\%) with age-related macular degeneration, and 10 (5\%) with stroke. Most of the caregivers were retired, however $42(22 \%)$ caregivers were still carrying out professional activity, among them 16 caregivers had declared that supportive care had an impact on their professional life, and required time arrangement $(n=1)$ or resignation $(n=10)$. A total of $23(13 \%)$ caregivers declared average household incomes below $€ 1500$ per month. At inclusion, 5 (3\%) asked for financial support and 25 (14\%) caregivers asked for professional support (Table 1$)$.

\section{Caregiver involvement at baseline and at different timepoints}

Most of the caregivers were involved at baseline in five main areas of patient activities: moral and emotional support ( $n=172,96 \%)$, medical decision support $(n=172,96 \%)$, medical support $(n=136,76 \%)$; domestic chores $(n=120,67 \%)$, administrative management $(n=119,66 \%)$. Half of the caregivers declared to provide financial assistance $(n=94,53 \%)$ (Table 1). A significantly decreased rate of caregivers involved in medical support and financial assistance from baseline to $M 12$, and financial assistance and medical decision support from baseline to M24 in the supportive intervention was observed. In the control group, the rate of caregivers providing help in medical decision support from baseline to M12, and in moral and emotional support from baseline to M12 and to M24 was significantly reduced (Supplementary Figure SI).

\section{Health-related quality of life (SF-36)}

In mean SF-36 PCS and MCS scores, no clinically and statistically significant decrease was observed from baseline to M12 or baseline to M24 in each group. However, a statistical difference for PCS from baseline to M12 was noted in each group (Table 2).

Regarding the nine individual SF-36 subscales, the control group showed a clinically and statistically significant decrease in the mean score for physical functioning and bodily pain at M12 and M24, role physical, social functioning and vitality at M12. In the supportive intervention group, a significant decrease in the mean score for physical functioning at M12 and M24, and role physical, and social functioning at M12 (supplementary Figure SII). 
Caregivers with a HRQoL score categorized as stable, deteriorated or improved in SF-36 PCS and MCS at $\mathrm{M} 12$ and at M24 are presented in each group in the Figure 2. Around one third of the caregivers in the control group showed a deteriorated SF-36 PCS and MCS, and whereas about $10 \%$ of them showed an improved PCS, about $25 \%$ reported an improved MCS. The same trend was observed in the supportive intervention group, however a third of caregivers (up to $37 \%$ at M24) declared an improved MCS.

\section{Anxiety and Depression (HADS)}

Whereas no difference in anxiety mean score was reported, depression mean score was clinically and statistically increased in the control group at M12 and M24. No differences in anxiety and depression mean scores were reported in the supportive intervention group regardless of each timepoint (Table 2).

The rate of caregivers with worsening anxiety and depression at M24 in the control group was respectively $13.5 \%$ and $23 \%$, and whereas $24 \%$ of the caregivers showed improved anxiety, less than $3 \%$ showed improved depression. In the supportive intervention group, worsening anxiety and depression at M24 was respectively reported in $17 \%$ and in $18 \%$ of the caregivers, and improved anxiety and depression respectively in about 14 and $7 \%$ of the caregivers (Figure 2).

\section{Burden (ZBI)}

Mean ZBI score was not clinically different from baseline to each timepoint in each group. To note, a statistically significant increased ZBI score at M12 and M24 was observed in the control group (Table 2).

Caregivers in the control group showed $26 \%$ of worsening ZBI score and $8 \%$ reported less burden at M24. In the supportive intervention group, $29 \%$ reported a worsening ZBI and a higher number of caregiver (14\%) showed less burden at M24 (Figure 2).

\section{Longitudinal analysis.}

The mixed models for repeated measures (longitudinal analyses) did not show clinically significant differences at M12 or at M24 for SF-36, HADS anxiety, and ZBI (Supplementary Table SIII). However, a significant change in HADS depression score at M24 was identified in the control group.

\section{Discussion}

These results are issued from an ambitious experimental project and provided with a limited but relatively large sample of data $(n=179)$ measures of HRQoL and physical and mental health in the caregivers enrolled. The current analysis of the ICE study did not allow to evidence differences in SF-36 PCS and MCS summary scores mean change over time, neither in HADS anxiety and burden ZBI scores. However, HADS depression scores significantly increased at M12 and M24 exclusively in the control group, and also confirmed at M24 in the mixed models. Regarding SF-36 subscales analysis, a significant decrease in physical functioning at M12 and M24, in role physical and social functioning at M12 in each group, and in the control group decreased scores for bodily pain, and vitality at M12. Considering data at the 
individual level, in the control group, the proportion of caregivers with worsening depression remains limited (24\%). Interestingly, despite no difference in mean score in ZBI burden was evidenced, $30 \%$ of the caregivers had worsening burden; indeed, in the absence of a specifically validated MID, the interpretation of burden score used the conventional definition which may have minimized the possibility to evidence differences.

The deterioration in HRQoL physical sub-dimensions reported by caregivers in the first 2 years of ICE study is consistent with previously reported results.(25-27) Caregiving stress has been reported to correlate with physical impairments at two years, and caregivers are more likely to develop arthritis, chronic back pain, or heart disease related to high level of stress.(26)

In the supportive group, no significant change in depression was noted, and less HRQoL sub-dimensions with significant deterioration were reported. These results may indirectly reflect a benefit from the intervention involving social workers. Previous studies investigating intervention in caregivers of patients with dementia also showed quite limited but significant influence on caregiver depression and burden. (28)

Consistently, intervention targeting self-care and interpersonal connections of caregivers and symptom management of adult cancer patients have been reported to alleviate depression and improve caregiver HRQoL.(29) In addition, the rate of caregivers requesting professional or financial support only slightly varied in the two years from inclusion regardless the allocation group, and notably in the supportive intervention group which may be surprising. In practical, social workers reported that they mainly had a role of listening, and caregivers had not taken advantage of the full scope of opportunities the social workers may provide. The additional support provided in the supportive intervention group led to results consistent with Stenberg et al, showing that caregivers with more social relationships presented a better mental health and less depression, and those with reduced social contacts higher perceived burden.(25)

Caregivers play a critical role in cancer patient disease management and control and assume in turn different role.(30) Earlier and better recognition of their contributory participation in patient care need to be encouraged. Further issues had arisen regarding the growing recognition of caregiver specific needs, and the most appropriate assistance to provide to caregivers. Hence, caregiver compromised HRQoL will also adversely impact the delivery of effective patient care.(31) Greater access to caregivers, along with the development of education programs may help health professionals to identify caregivers, and help caregivers to self-recognize their own contribution, and to more easily access to dedicated studies.

The ICE study had several limits. Whereas the cohort enrolled nearly 200 caregivers, the sample size remains reduced faced with the initial expectations. Specifically, the sample size did not allow to perform comparisons between allocation groups. This mixed population consequently gathered informal caregivers of elderly with different diseases. Whereas caregiver needs and requirements evolve and change for each disease trajectory and are obviously different regarding the initial pathology, the statistical power was not large enough to conduct the predefined subgroups analyses for each pathology. 
Difficulties in appropriate identification and access to patient primary caregiver has been previously reported to be a difficult task for clinicians $(32,33)$, and may partly explain limited caregivers enrolment in ICE study. Caregivers have been qualified as "the invisible patient",(34) and the importance of family caregiving that underspin the health status of patients need to be emphasized. To date, no specific assessment of living conditions including accurate identification of informal caregiving is performed at the initiation of patient management. Hence conducting research on caregivers is a challenging issue.

Both patient and caregiver HRQoL and their respective needs have to be better identified and appropriately addressed with adequate methods/resources (adapted education courses, accompaniment of self-recognition of caregiver status) and timing. Recent policy developments emerge and new institutional structures are created to alleviate caregiver burden.(36, 37) Providing to caregivers an opportunity to rest and recover is essential for maintaining their capacity to care for their loved ones, and greater recognition of needs, issues and rights has to be assessed at specific periods in the disease trajectory. In particular, respite and emotional needs of caregivers appear to be particularly important at specific timepoints, notably in the period 6 to 12 months after cancer diagnosis.(38)

\section{Conclusion}

Appropriate support need to be proposed to reduce depression at 1 and 2 years and therefore improve the global caregiver quality of life. Further studies with collaborations between social and health systems will help to better identify caregiver needs, and provide an adequate assistance to this important, vulnerable and invisible population.

\section{Declarations}

\section{Ethics approval.}

This study received approval from the local Ethics Committee (Comité de Protection des Personnes Est-II, Besançon) on November $4^{\text {th }}, 2014$ and from the French advisory committee on information processing research in the field of health (Comité Consultatif sur le Traitement de l'Information en Matière de Recherche dans le Domaine de la Santé, CCTIRS) (protocol number 15.022-bis) on March $5^{\text {th }}, 2015$. Approval from the National authority for the protection of privacy and personal data (Commission Nationale Informatique et Libertés, CNIL) was obtained on June $23^{\text {rd }}, 2015$.

\section{Consent to participate.}

Written informed consent from both patients and caregivers were obtained from each participant prior to inclusion in the study.

\section{Consent for publication.}


Authors had full access to all data in the study, reviewed this manuscript and accepted responsibility to submit for publication.

\section{Availability of data and materials.}

The datasets analysed during the current study are available from the corresponding author on reasonable request.

\section{Competing interests.}

The authors declare that they have no competing interests.

\section{Funding.}

The study received funding from the Agence Nationale de La Recherche (ANR), Institut National du Cancer (INCa), La Ligue Contre le Cancer, Roche Foundation, and la Caisse Nationale de Solidarité pour I'Autonomie (CNSA). The funders had no role in the study design, data collection, data analysis, data interpretation, or writing of the report.

\section{Authors contributions.}

C.L., M.B., T.S.D.Y., P.F., M.G., P.M. participated in the design of the study. C.Q. ensured the coordination of social worker intervention and administrative support. M.M. was responsible for data collection. M.M. was responsible for the data management. S.D. drafted the manuscript. A.A. was responsible for the study methodology and drafted the manuscript. A.P. coordinated the study, realized statistical analysis and drafted the manuscript. V.N. was the principal study coordinator, participated in the design of the study and drafted the manuscript. All authors reviewed the manuscript.

\section{Acknowledgements.}

This research was supported by institutional partners: The Communal Centers for Social Action of Dijon and Besançon, the General Council of the Doubs and the Territoire de Belfort; the Caisse d'Assurance Retraite et de la Santé au Travail (CARSAT) Bourgogne and Franche-Comté (Pension and Occupational Health Insurance Fund) and the Agricultural Social Mutual. The authors thank all the investigators and all clinical research assistants involved in the study. We also would like to thank the Aidants Attitude organization for the booklet and all patients and caregivers that participated in the study. The authors want to mention that the large program ICE was initiated by the late Professor F. Bonnetain, responsible of the methodology and quality of life in cancerology unity of the hospital of Besançon, France.

\section{Reference}

1. Colombo F, Llena-Nozal A, Mercier J, Tjadens F. Help wanted? Providing and paying for long-term care. 2011 [updated 2011]. 
2. COFACE. http://www.coface-eu.org/resources/publications/charter-for-family-carers/. European Charter for Family Carers2009. 2017 6/11/2017.

3. Fonareva I, Oken BS. Physiological and functional consequences of caregiving for relatives with dementia. IntPsychogeriatr. 2014 5/2014;26(5):725-47.

4. Jowsey T, McRae I, Gillespie J, Banfield M, Yen L. Time to care? Health of informal older carers and time spent on health related activities: an Australian survey. BMCPublic Health. 2013 4/22/2013;13:374.

5. Brimblecombe N, Fernández J-L, Knapp M, Rehill A, Wittenberg R. Unpaid care in England: future patterns and potential support strategies. In: Personal Social Services Research Unit L, editor. 2018.

6. Bouget D, Spasova S, Vanhercke B. Work-life balance measures forpersons of working age with dependent relatives in Europe. A study of national policies,European Social Protection Network (ESPN). European Social Protection Network (ESPN). 2016 1/1/2016.

7. Brimblecombe N, Pickard L, King D, Knapp M. Perceptions of unmet needs for community social care services in England. A comparison of working carers and the people they care for. Health SocCare Community. 2017 3/2017;25(2):435-46.

8. Zigante V. Informal care in Europe. Exploring formalisation, availability and quality. Social Affairs and Inclusion (European Commission ,London School of Economics and Political Science (LSE). 2018 6/11/2018.

9. Commission E. Informal care in Europe. Exploring formalisation, availability and quality. Brussels, Belgium.: European commission., 2018.

10. Besnard X, Brunel M, Couvert N, Roy D. Les proches aidants des seniors et leur ressenti sur l'aide apportée.Résultats des enquêtes "CARE" auprès des aidants (2015-2016) 2019 [updated 2019]. Available from: https://drees.solidarites-sante.gouv.fr/sites/default/files/2020-07/dd45.pdf.

11. INSEE. En Bourgogne-Franche-Comté, une population encore en baisse au 1er janvier 2021. 2021 may 2021. Report No.

12. Pozet A, Lejeune $C$, Bonnet M, Dabakuyo S, Dion M, Fagnoni P, et al. Evaluation of efficacy and efficiency of a pragmatic intervention by a social worker to support informal caregivers of elderly patients (The ICE Study): study protocol for a randomized controlled trial. Trials. 2016 11/3/2016;17(1):531.

13. LOCKE. Validation of Single Item Linear Analog Scale Assessment of Quality of Life in Neuro Oncology Patients. NIHPA Manuscripts. 20002000.

14. Ware JE, Sherbourne CD. The MOS 36-item short-form health survey (SF-36). I. Conceptual framework and item selection. Med Care. 1992 1/1/1992 1992;30(6):473-83.

15. Leplege A, Ecosse E, Verdier A, Perneger TV. The French SF-36 Health Survey: translation, cultural adaptation and preliminary psychometric evaluation. JClinEpidemiol. 1998 11/1998;51(11):1013-23.

16. Leplege A, Mesbah M, Marquis P. [Preliminary analysis of the psychometric properties of the French version of an international questionnaire measuring the quality of life: the MOS SF-36 (version 1.1)]. RevEpidemiolSante Publique. 1995 1995;43(4):371-9. 
17. Razavi D, Delvaux N, Farvacques C, Robaye E. Validation de la version française du HADs dans une population de patients cancéreux hospitalisés. Rev Psychol Appl. 1989 1/1/1989;39(4):285-307.

18. Zarit SH, Reever KE, Bach-Peterson J. Relatives of the impaired elderly: correlates of feelings of burden. Gerontologist. 1980 1/1/1980;20(6): 649-55.

19. Hebert R, Bravo G, Girouard D. Fidélité de la traduction française de trois instruments auprès des aidants naturels de malades déments. Canadian Journal on AgingLa Revue Canadienne du vieillissement, Centre de Recherche en Gérontologie et Gériatrie, Hôpital d'Youville de Sherbrooke. 2021 2021;12(3):324-37.

20. Hebert R, Leclerc G, Bravo G, Girouard D, Lefrancois R. Efficacy of a support group programme for care-givers of demented patients in the community: a randomized controlled trial. ArchGerontolGeriatr. 1994 1/1994;18(1):1-14.

21. Razavi D, Delvaux N, Farvacques C, Robaye E. Screening for adjustment disorders and major depressive disorders in cancer in-patients. BrJPsychiatry. 1990 1/1990;156:79-83.

22. Seng BK, Luo N, Ng WY, Lim J, Chionh HL, Goh J, et al. Validity and reliability of the Zarit Burden Interview in assessing caregiving burden. AnnAcadMedSingap. 2010 10/2010;39(10):758-63.

23. Jaeschke R, Singer J, Guyatt GH. Measurement of health status. Ascertaining the minimal clinically important difference. Control ClinTrials. 1989 12/1989;10(4):407-15.

24. Puhan MA, Schunemann HJ, Buesching G, vanOort E, Spaar A, Frey M. COPD patients' ability to follow exercise influences short-term outcomes of rehabilitation. EurRespirJ. 2008 2/2008;31(2):30410.

25. Stenberg U, Ruland CM, Miaskowski C. Review of the literature on the effects of caring for a patient with cancer. Psychooncology. 2010 10/2010;19(10):1013-25.

26. Kim Y, Carver CS, Shaffer KM, Gansler T, Cannady RS. Cancer caregiving predicts physical impairments: roles of earlier caregiving stress and being a spousal caregiver. Cancer. 2015 Jan 15;121(2):302-10. PubMed PMID: 25209592. Epub 2014/09/12. eng.

27. Ochoa CY, Buchanan Lunsford N, Lee Smith J. Impact of informal cancer caregiving across the cancer experience: A systematic literature review of quality of life. Palliative \& supportive care. 2020 Apr;18(2):220-40. PubMed PMID: 31588882. Epub 2019/10/08. eng.

28. Pinquart $M$, Sorensen $S$. Helping caregivers of persons with dementia: which interventions work and how large are their effects? IntPsychogeriatr. 2006 12/2006;18(4):577-95.

29. Fu F, Zhao H, Tong F, Chi I. A Systematic Review of Psychosocial Interventions to Cancer Caregivers. Front Psychol. 2017 2017;8:834.

30. Law S, Ormel I, Babinski S, Kuluski K, Quesnel-Vallee A. Caregiving is like on the job training but nobody has the manual": Canadian caregivers' perceptions of their roles within the healthcare system. BMCGeriatr. 2021 6/30/2021;21(1):404.

31. Lambert SD, Yoon H, Ellis KR, Northouse L. Measuring appraisal during advanced cancer: psychometric testing of the appraisal of caregiving scale. PatientEducCouns. 2015 5/2015;98(5):633-9. 
32. Hazell CM, Jones CJ, Pandey A, Smith HE. Barriers to recruiting and retaining psychosis carers: a case study on the lessons learned from the Caring for Caregivers (C4C) trial. BMCResNotes. 2019 12/17/2019;12(1):810.

33. van Knippenberg RJM, de Vugt ME, Smeets CMJ, Myin-Germeys I, Verhey FRJ, Ponds RW. Dealing with daily challenges in dementia (deal-id study): process evaluation of the experience sampling method intervention 'Partner in Sight' for spousal caregivers of people with dementia. Aging MentHealth. 2018 9/2018;22(9):1199-206.

34. Adelman RD, Tmanova LL, Delgado D, Dion S, Lachs MS. Caregiver burden: a clinical review. JAMA. 2014 3/12/2014;311(10):1052-60.

35. Ferrell B, Wittenberg E. A review of family caregiving intervention trials in oncology. CA Cancer JClin. 2017 7/8/2017;67(4):318-25.

36. Lefranc A, Perol D, Plantier M, Chatelain P, de Rohan-Chabot $H$, Schell M. Assessment of informal caregiver's needs by self-administered instruments: a literature review. EurJPublic Health. 2017 10/1/2017;27(5):796-801.

37. Zebrak KA, Campione JR. The Effect of National Family Caregiver Support Program Services on Caregiver Burden. JApplGerontol. 2021 9/2021;40(9):963-71.

38. Stiller A, Goodwin BC, Crawford-Williams F, March S, Ireland M, Aitken JF, et al. The Supportive Care Needs of Regional and Remote Cancer Caregivers. CurrOncol. 2021 8/9/2021;28(4):3041-57.

\section{Tables}

Table 1. Patients and caregivers baseline characteristics, in the supportive interventional group and in the control group. 


\begin{tabular}{|c|c|c|}
\hline $\begin{array}{l}\text { SIG } \\
(n=90)\end{array}$ & $\begin{array}{l}\text { CG } \\
(n=89)\end{array}$ & $\begin{array}{l}\text { All randomized } \\
\text { caregivers } \\
(n=179)\end{array}$ \\
\hline
\end{tabular}

\section{Patients}

\section{Gender}

Male

$39(43) \quad 40(45) \quad 79(44)$

Female

$51(57)$

49 (55)

$100(56)$

Age

$73(60-$

94)

$73(60-$

94)

\section{Disease}

Cancer

$46(51) \quad 46(51) \quad 92(52)$

Colorectal cancer

$11(12) \quad 10(10) \quad 21(12)$

Prostate cancer

$12(13) \quad 13(15) \quad 25(14)$

Breast cancer

$23(26) \quad 23(26) \quad 46(26)$

Neuro-degenerative disease

$33(37) \quad 33(37) \quad 66(37)$

Alzheimer disease

$23(26) \quad 23(26) \quad 46(26)$

Idiopathic Parkinson's disease

$10(11) \quad 10(11) \quad 20(11)$

AMD

$6(6)$

$5(6)$

11 (6)

Stroke

$5(6)$

$5(6)$

$10(5)$

\section{Cancer severity $(n=92)$}

Non metastatic / adjuvant

$27(59) \quad 27(59) \quad 54(59)$

Metastatic/advanced

$19(41)$

Missing

0

$18(39)$

$37(40)$

Alzheimer severity $(n=46)$

Low: MMSE $\geq 26$

2 (9)

0

2 (4)

Mild: $20 \leq M M S E<26$

$12(52)$

$13(57)$

25 (55)

Moderate: $10 \leq \mathrm{MMSE}<20$

8 (35)

$10(43)$

18 (39)

Severe: $M M S E<10$

1 (4)

0

$1(2)$

Parkinson severity $(n=20)$

Stade I

$1(10)$

$2(20)$

$3(15)$ 


\begin{tabular}{|c|c|c|c|}
\hline Stade II & $4(40)$ & $4(40)$ & $8(40)$ \\
\hline Stade III & $4(40)$ & $2(20)$ & $6(30)$ \\
\hline Stade IV & $1(10)$ & $2(20)$ & $3(15)$ \\
\hline \multicolumn{4}{|l|}{ AMD severity $(n=11)$} \\
\hline Retrofoveolar exudative & $2(33)$ & $4(80)$ & $6(55)$ \\
\hline Extrafoveolar exudative & $2(33)$ & $1(20)$ & $3(27)$ \\
\hline Missing & $2(33)$ & 0 & $2(18)$ \\
\hline \multicolumn{4}{|l|}{ Stroke severity $(n=10)$} \\
\hline Barthel score & $\begin{array}{l}95(40- \\
100)\end{array}$ & $\begin{array}{l}100(65- \\
100)\end{array}$ & $100(40-100)$ \\
\hline Rankin score & $1(0-5)$ & $1(0-4)$ & $1(0-5)$ \\
\hline \multicolumn{4}{|l|}{ Caregivers } \\
\hline \multicolumn{4}{|l|}{ Gender } \\
\hline Male & $33(37)$ & $26(29)$ & $59(33)$ \\
\hline Female & $57(63)$ & $63(71)$ & $120(67)$ \\
\hline Age & $\begin{array}{l}67(29- \\
92)\end{array}$ & $\begin{array}{l}65(34- \\
92)\end{array}$ & $65(29-92)$ \\
\hline \multicolumn{4}{|l|}{ Marital status / living situation } \\
\hline Married, common-law couple, PACS couple & $71(79)$ & $79(89)$ & $150(84)$ \\
\hline Other (single, separated, divorced or widowed) & $19(21)$ & $10(11)$ & $29(16)$ \\
\hline \multicolumn{4}{|l|}{$\begin{array}{l}\text { Caregiver-patient relationship (caregiver taking care } \\
\text { of his/her) }\end{array}$} \\
\hline Spouse & $59(66)$ & $59(66)$ & $118(66)$ \\
\hline Mother/Father & $20(22)$ & $22(25)$ & $42(23)$ \\
\hline Other (friend, neighbour, sister, etc) & $11(12)$ & $8(9)$ & $19(11)$ \\
\hline \multicolumn{4}{|l|}{ Professional situation } \\
\hline Professional activity & $22(24)$ & $20(22)$ & $42(22)$ \\
\hline Retired & $62(69)$ & $61(69)$ & $123(69)$ \\
\hline etc) Other (sick leave, unemployment, job training, & $6(7)$ & $8(9)$ & $14(9)$ \\
\hline $\begin{array}{l}\text { Caregiving impact on caregiver professional life } \\
(n=42)\end{array}$ & $7(32)$ & $9(43)$ & $16(37)$ \\
\hline
\end{tabular}


Type of impact on caregiver professional life $(n=16)$

$\begin{array}{llll}\text { Work-time arrangements } & 0 & 1(11) & 1(6) \\ \text { Resignation } & 5(71) & 5(56) & 10(63) \\ \text { Other } & 2(29) & 3(33) & 5(31)\end{array}$

Past or current professional occupation

Farmer

Craftsman, shopkeeper, business owner

Executive, intellectual profession

Middle level profession

Employee

Worker

Other (without profession, job training or student)

Not specified

\section{Household incomes $€ /$ month}

$<€ 800$

From $€ 800$ to $€ 1,500$

From $€ 1,501$ to $€ 3,000$

Up to $€ 3,001$

Not specified

Caregiving impact on caregiver financial situation

Financial help requested by the caregiver

Professional help requested by the caregiver

Number of caregivers involved in patient activities at baseline

Daily activities

Domestic chores

Administrative management

Medical support

Physical support services
0

$6(7)$

$22(25)$

$9(10)$

$46(51)$

3 (3)

$2(2)$

$8(9)$

$10(6)$

$3(2)$

2 (2) $8(4)$

$18(20)$

7 (8)

$16(9)$

9 (5)

$6(7)$

$2(1)$

0
$2(2)$

40 (22)

$91(51)$

$3(3)$

3 (3)

$6(3)$

$8(9)$

9 (10)

$17(10)$

$45(50)$

41 (46)

$86(48)$

$24(27)$

26 (29)

50 (28)

$10(11)$

10 (11)

20 (11)

5 (6)

4 (4)

9 (5)

3 (3)

2 (2)

5 (3)

13 (14)

12 (13)

25 (14)

$25(14)$




\begin{tabular}{|llll|} 
Financial assistance & $49(54)$ & $45(48)$ & $94(53)$ \\
\hline Moral and emotional support & $86(96)$ & $86(97)$ & $172(96)$ \\
\hline Medical decision support & $71(79)$ & $71(80)$ & $172(96)$ \\
\hline
\end{tabular}

Data are median (range) or $\mathrm{n}(\%)$. Daily activities (grooming/dressing, etc); Domestic chores (cleaning, grocery shopping, meals, etc); Administrative management (accounting, mails, decisions); Medical support (accompaniment to medical appointments, medical cares). SIG: Supportive interventional; CG: control group; AMD: Age-related macular degeneration; MMSE: mini mental state examination; PACS: civil solidarity pact

Table 2. MOS SF-36, HADS and ZBI mean scores at baseline and mean score differences per group. 


\begin{tabular}{|c|c|c|c|c|c|c|c|}
\hline & \multirow[t]{3}{*}{ Allocation group } & \multicolumn{2}{|c|}{$\begin{array}{l}\text { Score } \\
\text { at baseline }\end{array}$} & \multicolumn{4}{|c|}{ Score difference } \\
\hline & & \multirow[b]{2}{*}{$n$} & \multirow[b]{2}{*}{$\begin{array}{l}\text { Mean } \\
\text { (SD) }\end{array}$} & \multicolumn{2}{|c|}{$\begin{array}{l}\text { M12- } \\
\text { baseline }\end{array}$} & \multicolumn{2}{|c|}{$\begin{array}{l}\text { M24 - } \\
\text { baseline }\end{array}$} \\
\hline & & & & $n$ & $\begin{array}{l}\text { Mean } \\
(\mathrm{SD})\end{array}$ & $n$ & $\begin{array}{l}\text { Mean } \\
\text { (SD) }\end{array}$ \\
\hline \multicolumn{8}{|l|}{ MOS SF-36 scores } \\
\hline \multirow[t]{2}{*}{$\begin{array}{l}\text { Physical Component } \\
\text { Summary }\end{array}$} & SIG & 90 & $\begin{array}{l}47.2 \\
(8.7)\end{array}$ & 59 & $\begin{array}{l}-4.1 \\
(8.2)^{\star}\end{array}$ & 43 & $\begin{array}{l}-2.4 \\
(6.9)\end{array}$ \\
\hline & CG & 89 & $\begin{array}{l}49.6 \\
(8.8)\end{array}$ & 53 & $\begin{array}{l}-4.2 \\
(8.4)^{*}\end{array}$ & 38 & $\begin{array}{l}-3.6 \\
(8.0)\end{array}$ \\
\hline \multirow[t]{2}{*}{$\begin{array}{l}\text { Mental Component } \\
\text { Summary }\end{array}$} & SIG & 90 & $\begin{array}{l}44.9 \\
(10.3)\end{array}$ & 59 & $\begin{array}{l}-0.3 \\
(11.5)\end{array}$ & 43 & $\begin{array}{l}0.1 \\
(10.8)\end{array}$ \\
\hline & CG & 89 & $\begin{array}{l}44.9 \\
(11.1)\end{array}$ & 53 & $-1.0(9.9)$ & 38 & $\begin{array}{l}0.5 \\
(10.9)\end{array}$ \\
\hline \multicolumn{8}{|l|}{ SF-36 subscales } \\
\hline \multirow[t]{2}{*}{ Physical Functioning } & SIG & 90 & $\begin{array}{l}85.9 \\
(18.9)\end{array}$ & 59 & $\begin{array}{l}-10.2 \\
(17.2) *\end{array}$ & 44 & $\begin{array}{l}-8.5 \\
(16.5)^{*}\end{array}$ \\
\hline & CG & 89 & $\begin{array}{l}85.5 \\
(18.0)\end{array}$ & 54 & $\begin{array}{l}-9.9 \\
(19.1)^{*}\end{array}$ & 38 & $\begin{array}{l}-9.0 \\
(18.1) *\end{array}$ \\
\hline \multirow[t]{2}{*}{ Role Physical } & SIG & 90 & $\begin{array}{l}69.4 \\
(38.2)\end{array}$ & 59 & $\begin{array}{l}-11.4 \\
(38.4) *\end{array}$ & 44 & $\begin{array}{l}-8.0 \\
(39.2)\end{array}$ \\
\hline & CG & 89 & $\begin{array}{l}75.0 \\
(37.9)\end{array}$ & 54 & $\begin{array}{l}-14.3 \\
(40.5) \star\end{array}$ & 39 & $\begin{array}{l}-7.9 \\
(41.1)\end{array}$ \\
\hline \multirow[t]{2}{*}{ Bodily Pain } & SIG & 90 & $\begin{array}{l}53.9 \\
(34.1)\end{array}$ & 59 & $\begin{array}{l}-7.1 \\
(28.1)\end{array}$ & 44 & $\begin{array}{l}-0.5 \\
(20.9)\end{array}$ \\
\hline & CG & 89 & $\begin{array}{l}68.1 \\
(32.2)\end{array}$ & 54 & $\begin{array}{l}-11.1 \\
(33.2) *\end{array}$ & 39 & $\begin{array}{l}-11.3 \\
(33.3) *\end{array}$ \\
\hline \multirow[t]{2}{*}{ Mental Health } & SIG & 90 & $\begin{array}{l}62.7 \\
(17.5)\end{array}$ & 59 & $\begin{array}{l}-2.4 \\
(17.0)\end{array}$ & 44 & $\begin{array}{l}-0.2 \\
(15.8)\end{array}$ \\
\hline & CG & 89 & $\begin{array}{l}62.9 \\
(20.5)\end{array}$ & 54 & $\begin{array}{l}-3.2 \\
(15.6)\end{array}$ & 39 & $\begin{array}{l}-1.4 \\
(17.7)\end{array}$ \\
\hline \multirow[t]{2}{*}{ Role Emotional } & SIG & 90 & $\begin{array}{l}67.4 \\
(38.7)\end{array}$ & 59 & $\begin{array}{l}-1.1 \\
(45.0)\end{array}$ & 43 & $\begin{array}{l}-3.1 \\
(45.3)\end{array}$ \\
\hline & CG & 89 & $\begin{array}{l}69.7 \\
(40.7)\end{array}$ & 53 & $\begin{array}{l}-3.1 \\
(37.7)\end{array}$ & 39 & $\begin{array}{l}-3.4 \\
(45.8)\end{array}$ \\
\hline Social Functioning & SIG & 90 & $\begin{array}{l}78.2 \\
(21.8)\end{array}$ & 59 & $\begin{array}{l}-7.4 \\
(25.0) *\end{array}$ & 44 & $\begin{array}{l}-4.0 \\
(22.7)\end{array}$ \\
\hline
\end{tabular}




\begin{tabular}{|c|c|c|c|c|c|c|c|}
\hline & $\mathrm{CG}$ & 89 & $\begin{array}{l}78.5 \\
(21.1)\end{array}$ & 54 & $\begin{array}{l}-9.9 \\
(24.1)^{*}\end{array}$ & 39 & $\begin{array}{l}-5.8 \\
(21.6)\end{array}$ \\
\hline \multirow[t]{2}{*}{ Vitality } & SIG & 90 & $\begin{array}{l}55.4 \\
(17.9)\end{array}$ & 59 & $\begin{array}{l}-3.0 \\
(16.3)\end{array}$ & 44 & $\begin{array}{l}-2.5 \\
(17.0)\end{array}$ \\
\hline & CG & 89 & $\begin{array}{l}59.3 \\
(20.5)\end{array}$ & 54 & $\begin{array}{l}-5.4 \\
(15.2) *\end{array}$ & 39 & $\begin{array}{l}-3.5 \\
(17.7)\end{array}$ \\
\hline \multirow[t]{2}{*}{ General Health } & SIG & 90 & $\begin{array}{l}62.9 \\
(16.4)\end{array}$ & 59 & $\begin{array}{l}-3.0 \\
(13.5)\end{array}$ & 44 & $\begin{array}{l}-1.3 \\
(13.4)\end{array}$ \\
\hline & CG & 89 & $\begin{array}{l}63.9 \\
(19.0)\end{array}$ & 54 & $\begin{array}{l}-1.8 \\
(11.4)\end{array}$ & 38 & $\begin{array}{l}-1.2 \\
(12.9)\end{array}$ \\
\hline \multirow[t]{2}{*}{ Health Transition } & SIG & 90 & $\begin{array}{l}48.0 \\
(15.5)\end{array}$ & 58 & $\begin{array}{l}1.3 \\
(21.2)\end{array}$ & 44 & $\begin{array}{l}-1.7 \\
(19.7)\end{array}$ \\
\hline & CG & 89 & $\begin{array}{l}50.3 \\
(17.5)\end{array}$ & 53 & $\begin{array}{l}-1.9 \\
(18.2)\end{array}$ & 39 & $\begin{array}{l}5.8 \\
(18.6)\end{array}$ \\
\hline \multicolumn{8}{|l|}{ HADS } \\
\hline \multirow[t]{2}{*}{ Anxiety } & SIG & 90 & $7.6(4.0)$ & 59 & $-0.1(3.2)$ & 43 & $\begin{array}{l}-0.4 \\
(3.1)\end{array}$ \\
\hline & CG & 89 & $7.9(4.3)$ & 54 & $0.3(3.9)$ & 39 & $\begin{array}{l}-0.4 \\
(3.2)\end{array}$ \\
\hline \multirow[t]{2}{*}{ Depression } & SIG & 90 & $4.3(3.4)$ & 59 & $0.6(3.9)$ & 43 & $\begin{array}{l}0.9 \\
(3.4)\end{array}$ \\
\hline & CG & 89 & $4.3(3.6)$ & 54 & $1.4(4.0) *$ & 39 & $\begin{array}{l}1.7 \\
(4.1)^{*}\end{array}$ \\
\hline \multicolumn{8}{|l|}{ ZBI } \\
\hline \multirow[t]{2}{*}{ Burden } & SIG & 87 & $\begin{array}{l}19.7 \\
(13.7)\end{array}$ & 54 & $\begin{array}{l}2.0 \\
(10.5)\end{array}$ & 44 & $\begin{array}{l}1.1 \\
(13.2)\end{array}$ \\
\hline & CG & 88 & $\begin{array}{l}17.7 \\
(15.1)\end{array}$ & 53 & $\begin{array}{l}6.4 \\
(11.4)^{*}\end{array}$ & 38 & $\begin{array}{l}6.7 \\
(15.7)^{\star}\end{array}$ \\
\hline
\end{tabular}

SIG: Supportive interventional group; CG: control group; SD: standard deviation; HADS: hospital anxiety and depression scale; ZBI: Zarit burden inventory. Number of questionnaires completed for the considered item at each timepoint are presented $(n)$. Minimal important differences (MID) was fixed at 5 points for SF-36 scores, 1.32 points for HADS anxiety score, 1.4 points for HADS depression score, and 7.2 points for ZBI score. In bold: MID significant; * paired t-test $p<0.05$

\section{Figures}






179 caregivers randomized

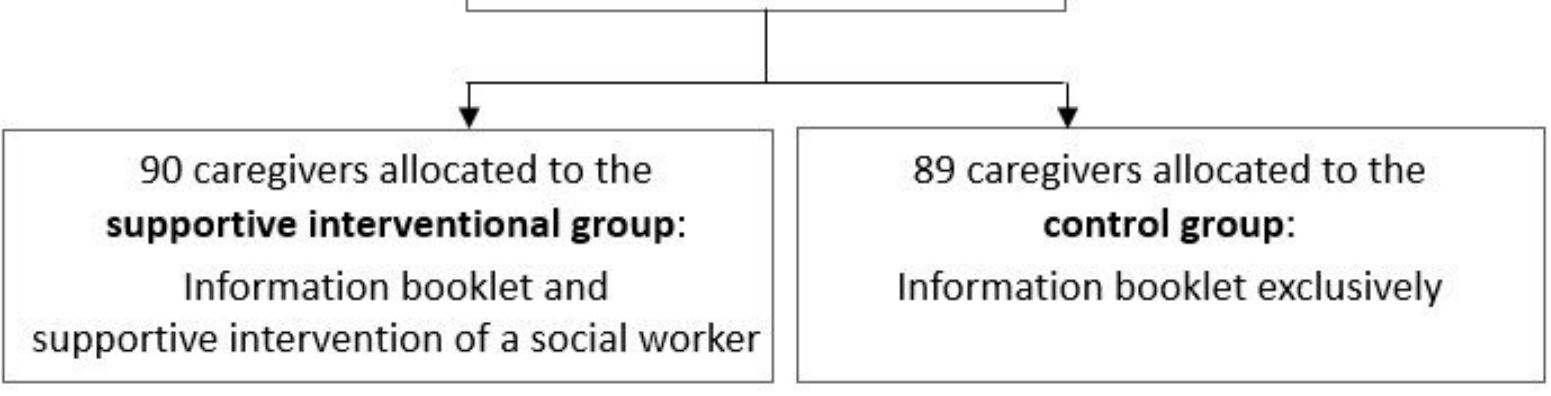

\begin{tabular}{|c|cc|}
\cline { 2 - 3 } Timepoints & $\begin{array}{c}\text { Evaluable } \\
\text { Caregivers }\end{array}$ & $\begin{array}{c}\text { Completed } \\
\text { Questionnaires }\end{array}$ \\
M0 & 90 & $90(100 \%)$ \\
M3 & 89 & $70(79 \%)$ \\
M6 & 85 & $65(76 \%)$ \\
M9 & 81 & $68(84 \%)$ \\
M12 & $75^{+}$ & $59(79 \%)$ \\
M15 & 70 & $52(74 \%)$ \\
M18 & 64 & $53(83 \%)$ \\
M21 & 60 & $45(75 \%)$ \\
M24 & $56 \neq$ & $44(79 \%)$ \\
\hline
\end{tabular}

\begin{tabular}{|cc|}
\hline $\begin{array}{c}\text { Evaluable } \\
\text { Caregivers }\end{array}$ & $\begin{array}{c}\text { Completed } \\
\text { Questionnaires }\end{array}$ \\
89 & $89(100 \%)$ \\
85 & $66(78 \%)$ \\
82 & $62(76 \%)$ \\
79 & $57(72 \%)$ \\
$77+$ & $54(70 \%)$ \\
71 & $51(72 \%)$ \\
65 & $47(72 \%)$ \\
59 & $40(68 \%)$ \\
$57 \neq$ & $39(68 \%)$ \\
\hline
\end{tabular}

\section{Figure 1}

\section{Trial profile}

Only questionnaires with at least one scored dimension were considered for analysis.

tStudy discontinuation at M12 (SIG: $n=15$ [caregiver decision, $n=12$, patient death, $n=3$ ]; CG: $n=12$ [caregiver decision $(n=8)$, patient death $(n=4)$ ]. 
¥ Study discontinuation at M24 (SIG: $n=34$ [caregiver decision, $n=23$; patient death, $n=9$; relocation in institution, $n=1$; relocation outside the region, $n=1$ ]; CG: $n=32$ [caregiver decision, $n=20$; patient death, $n=10$; caregiver death, $n=1$; relocation in institution, $n=1$;]

A) Supportive interventional group (SIG)

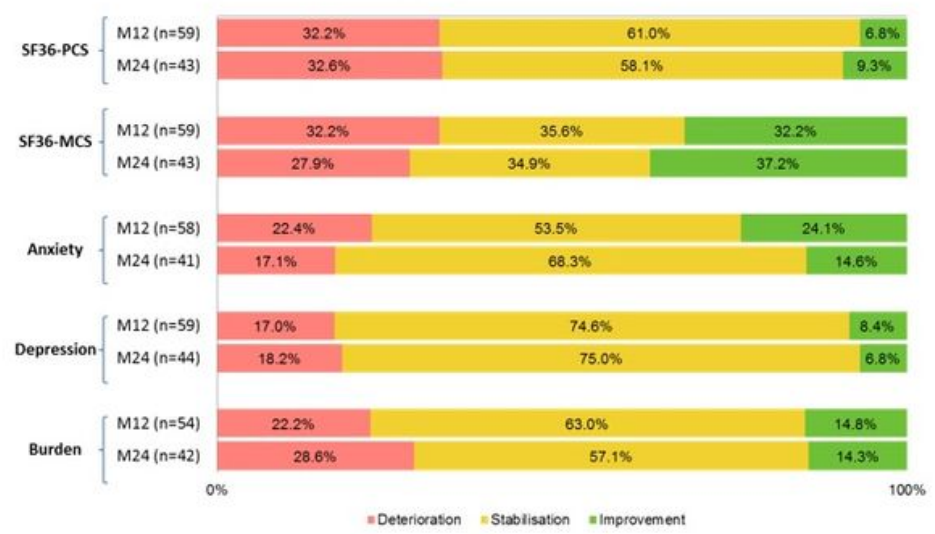

A) Control group (CG)

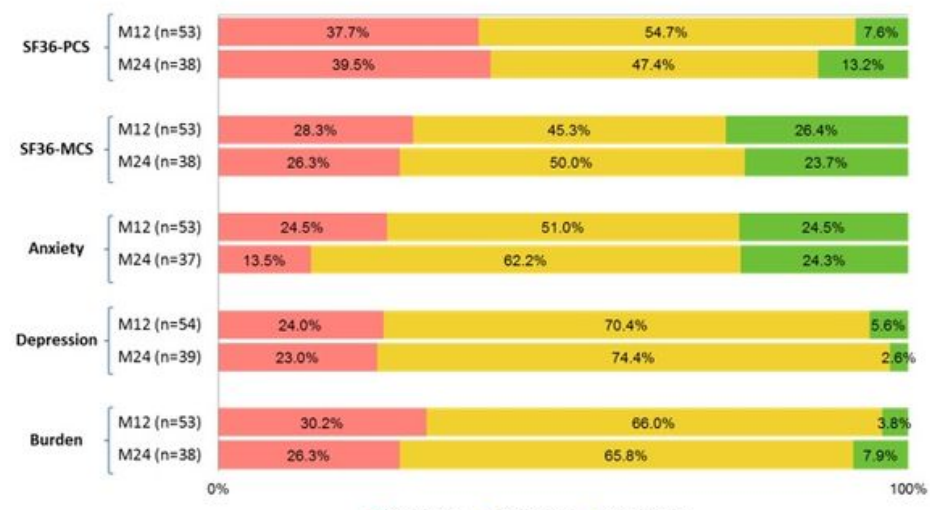

"Deterioration "Stablisation "Improvement

\section{Figure 2}

Rate of caregivers with deteriorated, stabilised, and improved HRQoL

SF-36 -PCS: physical SF-36 component summary; SF-36 - MCS: Mental SF-36 component summary. The minimal important difference (MID) used for quality of life categorization was fixed at 5 points for SF-36 scores, 1.32 points for HADS anxiety score, 1.4 points for HADS depression score, and 7.2 points for ZBI score. Number of questionnaires completed at each timepoint are presented ( $n$ )

\section{Supplementary Files}

This is a list of supplementary files associated with this preprint. Click to download.

- ICESupplementary.docx 